\title{
EDITORIAL - DOS DESAFIOS À BUSCA DE CONQUISTAS NA COMUNICAÇÃO CIENTÍFICA E NA DIVULGAÇÃO DA CIÊNCIA
}

\author{
EDITORIAL - DE LOS RETOS A LA BÚSQUEDA DE LOGROS EN LA \\ COMUNICACIÓN CIENTÍFICA Y LA DIVULGACIÓN DE LA CIENCIA
}

\author{
EDITORIAL - FROM CHALLENGES TO ACHIEVEMENTS IN SCIENCE \\ COMMUNICATION AND SCIENCE OUTREACH
}

\author{
Sebastião de Souza LEMES ${ }^{1}$ \\ José Anderson SANTOS CRUZ ${ }^{2}$ \\ Flávio Henrique MACHADO MOREIRA ${ }^{3}$ \\ Alexander Vinícius LEITE DA SILVA ${ }^{4}$
}

\begin{abstract}
A comunicação e divulgação científica, nessa era tecnológica, com a primazia dada à internet, representam a disseminação da informação e conhecimento, sendo uma simbologia para o processamento dos dados científicos, uma vez que os dados em si não são suficientes, sendo necessária a implementação de processos de comunicação (SANTOS CRUZ, 2020, p. 59).
\end{abstract}

Em um mundo de transformações e vivência acelerada pelas comunicações digitais, também a ciência se vem uma situação de renovação e adaptação aos novos meios socais digitais. A grande expansão tecnológica vivida nas últimas décadas e a consolidação da Tecnologias e Informação e Comunicação (TIC), como um meio de divulgação de informação e conhecimentos, científicos ou não, permitiu que ocorresse um a aproximação sem precedentes tanto entre a própria comunidade acadêmica, quanto entre esta e uma audiência não especializada, modificando não apenas a forma de apresentação do conhecimento, mas também o seu dinamismo e a constância de suas modificações, reduzindo cada vez mais as estratégias de construção um conhecimento pétreo de difícil revisão, em favor de um conhecimento mais

\footnotetext{
${ }^{1}$ Universidade Estadual Paulista (UNESP), Araraquara - SP - Brasil. Professor do Departamento de Educação e do Programa de Pós-Graduação em Educação Escolar. Editor. ORCID: https://orcid.org/0000-0002-0750-9294. E-mail: ss.lemes@gmail.com

${ }^{2}$ Fundação de Estudos Agrários Luiz de Queiroz (ESALQ), Piracicaba - SP - Brasil. Doutor pelo Programa de Pós-graduação em Educação Escolar (FCLAr/Unesp). Editor Adjunto e Executivo da RPGE. Assessoria Técnica para periódicos da Educação. Prof. Orientador PECEGE - MBA/USP ESALQ. Editor responsável pela Editora Ibero-Americana de Educação. ORCID: https://orcid.org/0000-0001-5223-8078. E-mail: andersoncruz.unesp@gmail.com

${ }^{3}$ Universidade Federal de São Carlos (UFSCAR), São Carlos - SP - Brasil. Assistente Editorial da RPGE. Mestre em Ciência Política. ORCID: https://orcid.org/0000-0002-2659-1692. E-mail: flavio.machadomoreira@gmail.com

${ }^{4}$ Centro Universitário Sagrado Coração (UNISAGRADO), Bauru - SP - Brasil. Graduando em Letras - Português e Inglês. Assistente Editorial da RPGE. Revisor e tradutor português/inglês. Bolsista PIBID/CAPES. ORCID: https://orcid.org/0000-0002-4672-8799. E-mail: alexandervinicius@editoraiberoamericana.com
}

RPGE- Revista on line de Política e Gestão Educacional, Araraquara, v. 25, n. 2, p. 1048-1052, maio/ago. 2021. e-ISSN: 1519-9029 
líquido, mais maleável e sujeito a ser visto e revisto constantemente através do imediatismo possibilitado pela comunicação virtual (VALÉRIO; PINHEIRO, 2008; SANTOS CRUZ, 2020).

Nesse mundo digital, o periódico acadêmico ganha cada vez mais relevância, se constituindo em uma manifestação de grande eficiência desse princípio de modificações e atualizações constantes preconizados pela Era Digital. Mas ainda enfrentam desafios sobre como se adequar a esse novo modo de divulgação científica, não apenas em questões de dinamismo, mas em questões de gerência própria, demandando a construção de uma equipe especializada que seja capaz de assumir as demandas de um trabalho editorial contínuo, quase ininterrupto, para que seja possível acompanhar o grande dinamismo produtivo e comunicativo existente, nesse sentido, as estratégias de gestão editorial e gestão do conhecimento se tornam desafios constantes.

Além de lidar com os desafios de como gerenciar, os periódicos, a equipe editorial e as informações e conhecimentos que serão disseminados e socializados através das contínuas publicações, também é necessário, para uma eficiente divulgação se estar atento aos indicadores de impactos, que podem ser entendidos como fatores que contribuem para a qualificação dos períodos e, consequente, validação dos dados neles divulgados (SANTOS CRUZ, 2020). Assim, numa era de grande influxo de informações e conhecimentos, a qualificação dos periódicos responsáveis por essa divulgação, se torna também um fator relevante que tem que ser observado, pois a busca da visibilidade do que é publicado é de grande importância para a consolidação de um meio de divulgação científica na atualidade. Com isso, o desenvolvimento de estratégias de divulgação científica que se foquem numa presença online, buscando maior visibilidade para os periódicos, se tornam frequentes entre os editores de revistas científicas (SANTILLÁNALDANA, 2018 apud SANTOS CRUZ, 2020, p. 65-66).

Por isso, ao se considerar a divulgação científica através desse uso de recursos tecnológicos de alta velocidade, para que o conhecimento seja acessível tanto para o público especializado quanto leigo, também se é necessário considerar a velocidade com que as transformações no próprio processo pelo qual as informações são medidas, considerando que o avanço pode ser mais rápido do que a capacidade de se adequar completamente, por parte dos periódicos, equipes editoriais e, mesmo, geradores do conhecimento científico, aos tempos antes de uma nova demanda e capacidade de transformações ser consolidada. Na era da internet, dados que podiam, há poucos anos, serem medidos em mega ou gigabytes, podem se transformar em pentabytes e a assim por diante, posando novos desafios para que essa divulgação ocorra de forma de eficiente (SANTOS CRUZ, 2020). 
Além dessas demandas sobre agilidade e fluidez oriunda da realidade vivida nos dias de hoje, também, para o processo de divulgação de informações científicas, é necessário que exista uma validação do conhecimento divulgado, esse trabalho é feito através de uma equipe responsável pela editoração das revistas, algo que é feito através da indexação dos periódicos em bases de dados confiáveis, além da sujeição a um sistema de avaliação (Qualis, h-index etc.).

Mesmo com todos os desafios impostos pela nova realidade que é vivenciada e se altera a cada dia, os periódicos se tornaram a forma mais utilizada para a divulgação científíca. Nesse papel, também mostram destaque ao enfrentar uma realidade que, além dos desafios impostos pelas questões de gestão e de adequação tecnológica, enfrentam uma situação de isolamento social que determinou a suspenção dos trabalhos presenciais em universidades e escolas ao redor do mundo, ocasionada pela pandemia do novo coronavírus.

Em uma situação, como a gerada pelo Covid-19, a divulgação científica online, especialmente através dos periódicos, se mostra como um instrumento eficiente, capaz de ajudar no enfrentamento do isolamento e proibição de atividades presenciais nas universidades, algo que em momentos passados poderia significar um grande entrave para a produção científica, foi visto como um desafio a ser superado e não uma barreira quase intransponível. A partir da possibilidade de acesso remoto e a presença da internet, tanto pesquisadores, quanto equipes editoriais, mantiveram os trabalhos de divulgação do conhecimento científico funcionando e possibilitando que existisse uma comunicação, quase em tempo real, entre os diversos locais do mundo que estudavam como combater a proliferação da pandemia.

Frente a uma crise sanitária de proporções mundiais, a adequação da divulgação e comunicação científica aos moldes da sociedade digital se mostrou eficiente em manter os princípios da geração de conhecimento, mostrando que apesar dos vários desafios enfrentados pelos periódicos, estes possuem a capacidade de acompanhar a sociedade e se adaptar a novas e mais maleáveis formas de revisão e disseminação dos conhecimentos científicos, permitindo o enfrentamento de situações difíceis e imprevistas de maneira mais eficiente, valorizando ainda mais o trabalho de pesquisadores e equipes de editoriais que estão tanto nos holofotes quanto nos bastidores da produção científica neste século.

Apesar de já se ter mostrado as condições e capacidade para superar os desafios que se apresentam além daqueles impostos pela Pandemia covid19, ainda existem muitas incertezas e barreiras que precisam ser superadas, para que a divulgação científica ocorra de forma honesta, acessível e eficiente, pois, um dos contrapontos que podem ser indicados sobre o acesso aberto à informação científica e à informação em geral é a capacidade de se gerar informações não 
confiáveis, até mesmo falsas, as fake news. Algo que, em princípio, poderia parecer insignificante se mostrou capaz de contestar informações e conhecimentos científicos validados ao longo de séculos, como a efetividade e importância da vacinação.

Em um momento que se conta com o maior alcance e dinamismo da divulgação do conhecimento científico - entendido como um conhecimento que se distingue por ter um alto grau de certeza e que é validado por teorias, métodos e técnicas que podem ser verificados e aprovados por outros pesquisadores (CHIBENI, 2020 apud SOUZA CRUZ, 2020, p. 47) -, também se pode observar um maior questionamento desse tipo de conhecimento e mesmo uma negação desse conhecimento como um todo. Até que ponto a divulgação do conhecimento científico deve se preocupar com a acessibilidade daquele conhecimento pelo público leigo no "democratizado" ambiente online? (NAVAS et al. 2020). Desafios, questões, respostas, adaptações e trabalho se colocam diante de pesquisadores e equipes editoriais na adequação dessa fluidez que indaga os tempos modernos, quando o acesso ao conhecimento se expande pela amplitude temática com que trata o assunto e se complexifica, com grande velocidade, pela exigência necessária de lógica e de sentido num universo de grande diversidade existencial.

\section{REFERÊNCIAS}

NAVAS, A. L. G. P. et al. Divulgação científica como forma de compartilhar conhecimento. CoDAS, v. 32, n. 2, e20190044, 2020. ISSN 2317-1782. DOI: https://doi.org/10.1590/2317$1782 / 20192019044$

SANTOS CRUZ, J. A. Gestão do conhecimento e gestão editorial: qualificadores da avaliação de periódicos da Área de Educação. Orientador: Prof. Dr. José Luís Bizelli. 2020. 283 f. Tese (Doutorado em Educação Escolar) - Faculdade de Ciências e Letras, Universidade Estadual Paulista, Araraquara, SP, 2021

VALERIO, P. M.; PINHEIRO; L. V. R. Da comunicação científica à divulgação.

Transinformação, Campinas, v. 20, n. 2, p. 159-169, maio/ago. 2008. Disponível em: https://www.scielo.br/j/tinf/a/jXWgggxgBhXfsT57JDVbghp/abstract/?lang=pt\#. Acesso em: 1 set. 2021. 


\section{Como referenciar este artigo}

LEMES, S. S.; SANTOS CRUZ, J. A.; MACHADO MOREIRA, F. H.; LEITE DA SILVA, A. V. Editorial - Dos desafios à busca de conquistas na comunicação científica e na divulgação da ciência. Revista on line de Política e Gestão Educacional, Araraquara, v. 25, n. 2, p. 10481052, maio/ago. 2021. e-ISSN:1519-9029. DOI: https://doi.org/10.22633/rpge.v25i2.15510

Submetido em: 01/08/2021

Publicado em: 01/08/2021 